importance of feedback inhibition and signal transduction cross-regulation in synovial inflammation. Further study of mechanisms by which SOCS proteins regulate inflammatory arthritis are likely to yield important insights into RA pathogenesis and cytokine regulatory networks in complex inflammatory diseases.

1. Feldmann, M., Brennan, F.M., and Maini, R.N. 1996. Role of cytokines in rheumatoid arthritis. Annu. Rev. Immunol. 14:397-440.

2. Yasukawa, H., Sasaki, A., and Yoshimura, A. 2000. Negative regulation of cytokine signaling pathways. Annu. Rev. Immunol. 18:143-164.

3. Nicola, N.A., et al. 1999. Negative regulation of cytokine signaling by the SOCS proteins. Cold Spring Harb. Symp. Quant. Biol. 64:397-404.

4. Schindler, C., and Darnell, J.E., Jr. 1995. Transcriptional responses to polypeptide ligands: the JAK-STAT pathway. Annu. Rev. Biochem. 64:621-651

5. Wang, F., Sengupta, T.K., Zhong, Z., and Ivashkiv, L.B. 1995. Regulation of the balance of cytokine production and the signal transducer and activator of transcription (STAT) transcription factor activity by cytokines and inflammatory synovial fluids. J. Exp. Med. 182:1825-1831.
6. Shouda, T., et al. 2001. Induction of the cytokine signal regulator SOCS3/CIS3 as a therapeutic strategy for treating inflammatory arthritis. J. Clin. Invest. 108:1781-1788. doi:10.1172/JCI200113568.

7. Frucht, D.M., et al. 2000. Stat4 is expressed in activated peripheral blood monocytes, dendritic cells, and macrophages at sites of Th1-mediated inflammation. J. Immunol. 164:4659-4664.

8. Hu, X., et al. 2002. Sensitization of IFN-gamma Jak-STAT signaling during macrophage activation. Nat. Immunol. 3:859-866.

9. Krause, A., Scaletta, N., Ji, J.D., and Ivashkiv, L.B. 2002. Rheumatoid arthritis synoviocyte survival is dependent on Stat3. J. Immunol. 169:6610-6616

10. Egan, P.J., Lawlor, K.E., Alexander, W.S., and Wicks, I.P. 2003. Suppressor of cytokine signaling-1 regulates acute inflammatory arthritis and $\mathrm{T}$ cell activation. J. Clin. Invest. 111:915-924. doi:10.1172/JCI200316156.

11. Firestein, G.S., and Zvaifler, N.J. 2002. How important are $T$ cells in chronic rheumatoid synovitis? II. T cell-independent mechanisms from beginning to end. Arthritis Rheum. 46:298-308.

12. Naka, T., et al. 1998. Accelerated apoptosis of lymphocytes by augmented induction of Bax in SSI-1 (STAT-induced STAT inhibitor-1) deficient mice. Proc. Natl. Acad. Sci. U. S. A. 95:15577-15582.

13. Alexander, W.S., et al. 1999. SOCS1 is a critical inhibitor of interferon gamma signaling and prevents the potentially fatal neonatal actions of this cytokine. Cell. 98:597-608.
14. Marine, J.C., et al. 1999. SOCS1 deficiency causes a lymphocyte-dependent perinatal lethality. Cell. 98:609-616.

15. De Sepulveda, P., et al. 1999. Socs 1 binds to mul tiple signalling proteins and suppresses steel factor-dependent proliferation. EMBOJ. 18:904-915.

16. Banerjee, A., Banks, A.S., Nawijn, M.C., Chen, X.P., and Rothman, P.B. 2002. Cutting edge: Suppressor of cytokine signaling 3 inhibits activation of NFATp. J. Immunol. 168:4277-4281.

17. Kinjyo, I., et al. 2002. SOCS1/JAB is a negative regulator of LPS-induced macrophage activation. Immunity. 17:583-591.

18. Nakagawa, R., et al. 2002. SOCS-1 participates in negative regulation of LPS responses. Immunity. 17:677-687.

19. Morita, Y., et al. 2000. Signals transducers and activators of transcription (STAT)-induced STAT inhibitor-1 (SSI-1)/suppressor of cytokine signaling-1 (SOCS-1) suppresses tumor necrosis factor alpha-induced cell death in fibroblasts. Proc Natl. Acad. Sci. U. S. A. 97:5405-5410.

20. Cacalano, N.A., Sanden, D., and Johnston, J.A. 2001. Tyrosine-phosphorylated SOCS-3 inhibits STAT activation but binds to p120 RasGAP and activates Ras. Nat. Cell. Biol. 3:460-465.

21. Diehl, S., et al. 2000. Inhibition of Th1 differentiation by IL- 6 is mediated by SOCS1. Immunity. 13:805-815

22. Ding, Y., et al. 2003. Suppressor of cytokine signaling 1 inhibits IL-10-mediated immune responses. J. Immunol. 170:1383-1391.

\title{
Autonomic "myasthenia": the case for an autoimmune pathogenesis
}

\author{
Daniel B. Drachman
}

Department of Neurology and Neuroscience, Johns Hopkins School of Medicine, Baltimore, Maryland, USA

J. Clin. Invest. 111:797-799 (2003). doi:10.1172/JCI200318180.

Of all neurological diseases, the one that virtually all third year medical students get right on final exams is myasthenia gravis (MG). MG is an autoimmune disorder that causes weakness and fatigue of skeletal muscles due to an antibody-mediated

\footnotetext{
Address correspondence to: Daniel B. Drachman, Department of Neurology and Neuroscience, Johns Hopkins School of Medicine, 600 North Wolfe Street, Baltimore, Maryland 21287-7519, USA.

Phone: (410) 955-5406; Fax: (410) 955-1961;

E-mail: dandrac@aol.com.

Conflict of interest: The author has declared that no conflict of interest exists.

Nonstandard abbreviations used: myasthenia gravis (MG); autoimmune autonomic neuropathy (AAN); musclespecific kinase (MuSK)
}

attack directed against AChRs at neuromuscular junctions (1). It is easy to learn and remember the pathogenesis, immunology, and treatment of MG because the pieces of the puzzle fit together nearly perfectly. In this issue of the JCI, Lennon et al. now provide intriguing evidence of another putative autoimmune disease of AChRs - autoimmune autonomic neuropathy (AAN) (2). They have shown that immunization of rabbits with a fragment of ganglionic AChR induces a condition that mimics the human disease. AAN is very rare but can be life threatening. It is manifested by autonomic disturbances affecting the sympathetic and parasympathetic nervous systems: abnormal gastrointestinal motility with stalled traffic in the intestines, impaired contraction and striking dilatation of the bladder, and disturbances of blood pressure, sweating, salivation, pupillary reactions, and sexual function (3). Based on these experiments and other evidence (4), Lennon et al. suggest that: (a) an antibody-mediated attack directed against neuronal AChRs of autonomic ganglia may be implicated in at least some cases of AAN; and (b) the autoimmune response in some of these patients may be triggered by a remote neoplasm that incidentally expresses the autoantigen. These new findings provide interesting insights into the concepts of autoimmune and paraneoplastic diseases of the nervous system, and information that may be useful for practical treatment of AAN.

\section{Five criteria for recognizing antibody-mediated autoimmune disease}

The list of candidate autoimmune diseases affecting every level of the nervous system is long and rapidly increasing. However, it is not simple to prove that a given disease is autoimmune in nature, and even more difficult to identify the autoimmune mechanisms and molecular 
targets of the disease process. I have proposed a set of criteria to evaluate the evidence for antibody-mediated pathogenesis in putative autoimmune diseases (5). This Commentary will analyze AAN in light of these criteria, and the implications of the results reported in this issue.

1. Autoantibodies are present in patients with the disease. This is a key starting point but by itself does not prove that a disease is antibody-mediated. Antibodies that bind to the $\alpha 3$ subunit of ganglionic AChRs have been detected in a substantial fraction (41\%) of patients with AAN (4), but significant antibody levels have also been detected in patients with other neurological diseases (6). These findings raise the following two questions.

First, why don't all patients with AAN have anti- $\alpha 3$ AChR antibodies? One rather unlikely possibility is that these antibodies may merely be markers of autoimmunity, not related to the pathogenesis of AAN, and therefore not present in all affected patients. Another alternative is that the antibodies were present early in the disease process and are now gone, or that they are all bound to the targeted AChRs and thereby removed from circulation. Finally, it is likely that at least some patients with a syndrome phenotypically similar to AAN do not have antibodies that bind to $\alpha 3$ AChRs. In some, the disorder may not be autoimmune in nature, while in others, antibodies that react with an antigen closely related, though not identical, to $\alpha 3 \mathrm{AChR}$ may exist. In the example of MG, approximately $15 \%$ of patients with generalized myasthenic weakness lack detectable anti-muscle AChR antibodies (1). Nevertheless, their serum immunoglobulins bind to AChR-expressing mammalian muscle cultures (7), and induce a reduction in AChRs upon passive transfer to mice (8-10). It has recently been shown that sera from approximately $40 \%$ of these patients have antibodies that bind to muscle specific kinase (MuSK), a protein that is closely linked to AChR, and plays a role in the clustering of AChRs during development of neuromuscular junctions (11). Whether anti-MuSK antibodies, or some other as yet unidentified antibodies, can account for the loss of AChRs in these patients is not yet known.
Second, why don't all patients with anti- $\alpha 3$ AChR antibodies have AAN? The Mayo group initially reported that only 5 of 12 patients with significant $\alpha 3$ AChR antibody titers had AAN (6). The other 7 patients had a variety of presumptively autoimmune syndromes: Isaacs syndrome, Lambert-Eaton syndrome, dementia, or sensory neuropathy. It is easy to explain the lack of AAN features in patients with autoantibodies against $\alpha 3$ AChRs, since autoantibodies are well known to be present in individuals without clinical disease. But why did such a high proportion of $\alpha 3$ AChR-antibody-positive patients have other autoimmune diseases? It is likely in at least some of these cases that the associated neoplasm presented multiple antigens that triggered other autoimmune responses (12). It is even conceivable that an immune response to $\alpha 3 \mathrm{AChR}$ could result in different clinical manifestations in different individuals.

2. Antibody interacts with the target antigen. The "smoking gun" of immunoglobulin bound to ganglionic AChRs has yet to be directly demonstrated in AAN. Nevertheless, there is persuasive circumstantial evidence to support this concept. Previous work has demonstrated that antibodies to $\alpha 3 \mathrm{AChR}$ bind to AChRs of ganglionic neurons (13). Furthermore, mice genetically lacking $\alpha 3 \mathrm{AChR}$ demonstrate the same dysautonomic features as patients with AAN (14). Finally, in the present report, autonomic ganglia from $\alpha 3$ AChR-immunized rabbits had electrophysiological features of postsynaptic failure of ACh transmission (2).

3. Passive transfer of antibody reproduces features of disease. This is arguably the most important piece of evidence required to link the disease to antibody-mediated pathogenic mechanisms $(15,16)$. Ideally, transfer of IgG from human AAN patients with $\alpha 3$ AChR antibodies to experimental animals should reproduce the clinical and electrophysiological features of the disease (4). This would confirm the specific pathogenic role of the antibody, and would rule out a cell-mediated disease mechanism. One would hope that passive transfer studies are in progress.

4. Immunization with antigen produces a model disease. This is the basis of the report by Lennon et al. (2), in which a model of AAN has been elegantly described. Immunization of rabbits with the extracellular domain of $\alpha 3$ AChR resulted in antibody production in most animals, and clinical disturbances of autonomic function consistent with AAN. The fact that the severity of symptoms corresponded with the level of antibodies is further persuasive evidence for the role of $\alpha 3 \mathrm{AChR}$ antibodies in the disease process.

5. Reduction of antibody levels ameliorates the disease. Rabbits that failed to develop $\alpha 3$ AChR antibodies did not develop disease, and those with low levels were less severely affected. Elsewhere these authors cite examples of a reduction in the severity of AAN in response to treatments that lower the antibody levels (4).

So far, the available evidence provides persuasive, if not yet definitive, support for antibody-mediated pathogenesis of at least some cases of AAN. Future studies are needed to evaluate the effects of passive transfer of serum from both $\alpha 3$ AChR-antibody-positive patients and -antibody-negative patients to recipient animals. From the clinical perspective, these studies highlight the importance of searching for an occult neoplasm in all patients with AAN, and raise the question of whether immunomodulatory treatment should be tried in all patients with AAN, with or without positive $\alpha 3 \mathrm{AChR}$ antibody results. Ultimately, knowledge of the antigen should lead to antigen-specific therapeutic strategies, like those being developed for MG (17).

1. Drachman, D.B. 1994. Myasthenia gravis. N. Engl J. Med. 330:1797-1810.

2. Lennon, V.A., Ermilov, L.G., Szurszewski, J.H., and Vernino, S. 2003. Immunization with neuronal nicotinic acetylcholine receptor induces neurological autoimmune disease. J. Clin. Invest. 111:907-913. doi:10.1172/JCI200317429.

3. Suarez, G., Fealey, R., Camilleri, M., and Low, P. 1994. Idiopathic autonomic neuropathy: clini $\mathrm{cal}$, neurophysiologic, and follow-up studies on 27 patients. Neurology. 44:1675-1682.

4. Vernino, S., et al. 2000. Autoantibodies to gan glionic acetylcholine receptors in autoimmune autonomic neuropathies. $N$. Engl. J. Med. 343:847-855.

5. Drachman, D.B. 1990. How to recognize an antibody-mediated autoimmune disease criteria. Res. Publ. Assoc. Res. Nerv. Ment. Dis. 68:183-186.

6. Vernino, S., Adamski, J., Kryzer, T.J., Fealey, R.D., and Lennon, V.A. 1998. Neuronal nicotinic ACh receptor antibody in subacute autonomic neuropathy and cancer-related syndromes. Neurology. 50:1806-1813.

7. Brooks, E.B., Pachner, A.R., Drachman, D.B., and Kantor, F.S. 1990. A sensitive rosetting assay for detection of acetylcholine receptor antibodies 
using BC3H-1 cells: positive results in 'antibodynegative' myasthenia gravis. J. Neuroimmunol. 28:83-93.

8. Drachman, D.B., de Silva, S., Ramsay, D., and Pestronk, A. 1987. Humoral pathogenesis of myasthenia gravis. Ann. NY Acad. Sci. 505:90-105.

9. Drachman, D., DeSilva, S., Ramsay, D., and Pestronk, A. 1987. "Sero-negative" myasthenia gravis: a humorally mediated variant of myasthenia. Neurology. 37(Suppl. 1):214

10. Burges, J., et al. 1994. Passive transfer of seronegative myasthenia gravis to mice. Muscle Nerve. 17:1393-1400.

11. Hoch, W., et al. 2001. Auto-antibodies to the receptor tyrosine kinase MuSK in patients with myasthenia gravis without acetylcholine receptor antibodies. Nat. Med. 7:365-368.

12. Darnell, R.B. 1996. Onconeural antigens and the paraneoplastic neurologic disorders: at the intersection of cancer, immunity, and the brain. Proc. Natl. Acad. Sci. U. S. A. 93:4529-4236.

13. Schoepfer, R., Halvorsen, S.W., Conroy, W.G., Whiting, P., and Lindstrom, J. 1989. Antisera against an acetylcholine receptor alpha 3 fusion protein bind to ganglionic but not to brain nicotinic acetylcholine receptors. FEBS Lett. 257:393-399.

14. Xu, W., et al. 1999. Megacystis, mydriasis, and ion channel defect in mice lacking the alpha3 neuronal nicotinic acetylcholine receptor. Proc. Natl. Acad. Sci. U. S. A. 96:5746-5751.

15. Toyka, K.V., Drachman, D.B., Pestronk, A., and Kao, I. 1975. Myasthenia gravis: passive transfer from man to mouse. Science. 190:397-399.

16. Rose, N., and Mackay, I. 1998. The autoimmune diseases: prelude. In The autoimmune diseases. $\mathrm{N}$. Rose and I. Mackay, editors. Academic Press. San Diego, California, USA. 1.

17. Drachman, D.B., et al. 2003. Specific immunotherapy of experimental myasthenia by genetically engineered APCs: the "guided missile” strategy. Ann. N. Y. Acad. Sci. In press.

\title{
Bone marrow: An extra-pancreatic hideout for the elusive pancreatic stem cell?
}

\author{
Vivian M. Lee and Markus Stoffel \\ Laboratory of Metabolic Diseases, The Rockefeller University, New York, New York, USA \\ J. Clin. Invest. 111:799-801 (2003). doi:10.1172/JCI200317063.
}

Diabetes, a leading cause of morbidity and mortality in industrialized countries, is caused by an absolute insulin deficiency due to the destruction of insulin secreting pancreatic $\beta$ cells (type 1 diabetes) or by a relative insulin deficiency due to decreased insulin sensitivity, usually observed in overweight individuals (type 2 diabetes). In both types of the disease, an inadequate mass of functional $\beta$ cells is the major determinant for the onset of hyperglycemia and the development of overt diabetes.

Maintenance of pancreatic $\beta$ cell mass results from a dynamic balance of neogenesis, proliferation, and apoptosis (1). These processes are adaptive since $\beta$ cells can proliferate physiologically in postnatal life (during growth or pregnancy), in response to injury, or in disease states such as obesity or other genetic forms of insulin

\footnotetext{
Address correspondence to: Markus Stoffel, The Rockefeller University, Laboratory of Metabolic Diseases, 1230 York Avenue, Box 292, New York, New York 10021, USA. Phone: (212) 327-8797; Fax: (212) 327-7997; E-mail: stoffel@mail.rockefeller.edu. Conflict of interest: The authors have declared that no conflict of interest exists. Nonstandard abbreviations used: embryonic day (E); enhanced green fluorescent protein (EGFP); glucose transporter 2 (Glut-2); hematopoietic stem cell (HSC); multipotential adult progenitor cell (MAPC); tyrosine kinase Kit (CD117).
}

resistance $(2,3)$. Therefore, the identification of pancreatic precursor (stem) cells and the mechanisms controlling their proliferation and differentiation are of central importance for developing novel approaches to treat diabetes.

\section{Pancreatic islet development \\ from gut endoderm}

Endocrine and exocrine cells of the pancreas are derived from a common set of epithelial cells from early gut endoderm (4). Although insulin expression can first be detected shortly after pancreatic bud formation, these cells are not believed to be the precursor of differentiated islet cells (5). Differentiated $\beta$ cells first appear around embryonic day 13 (E13) at the onset of the secondary transition, a phase of pancreatic organogenesis during which endocrine cells detach from the exocrine matrix, increase in number, and reorganize to form mature islets. Morphologically distinct cell clusters that exhibit the typical architecture of mature islets containing all endocrine cell types are first detected at about E17.5. During the perinatal period, $\beta$ cells of the islet undergo final differentiation, as evidenced by their ability to become glucose responsive in the first week of life.

Islet growth continues after birth, resulting from a combination of both an increase in cell size (hypertrophy), as well as cell number $(6,7)$. In addition, throughout much of life, small islets continue to develop from pancreatic ducts through neogenesis and proliferation. Islet mass turnover in rodents is slow and is believed to derive from two sources: replicating $\beta$ cells in pancreatic islets and neogenesis from pancreatic ducts (8). The capacity of $\beta$ cells to replicate is certainly important in the postnatal period, but may be more limited at later stages in life. Neogenesis of islets from pancreatic ducts, a two-step process that involves the expansion of duct epithelium and subsequent differentiation into mature islet cells, constitutes a second neogenic pathway that has been studied extensively in rodent models of pancreatic regeneration. This process is also believed to contribute to increased islet mass in mouse models of extreme insulin resistance where islets are often found in the vicinity of proliferating ducts. It should be noted that the concept of islet regeneration from duct epithelium has recently been challenged by lineage tracing studies that show an early separation of adult duct progenitors from endocrine cell lineages (9). Thus, the role of ductal epithelium in islet regeneration needs further investigation.

\section{Bone marrow: an extra-endodermal source of islet $\beta$ cells}

In this issue of the JCI, Ianus and colleagues (10) report an extra-pancreatic source of pancreatic $\beta$ cells that may play a role in $\beta$ cell turnover and possibly the adaptation of islet mass in response to physiological and environmental stimuli. In this elegant study, bone marrow cells that selectively express the enhanced green fluorescent protein (EGFP) if the insulin gene is actively transcribed, were transplanted into lethally irradiated recipient mice and gave rise to 